\title{
Contributing Factors for Turkey Consumption: An Empirical Analysis from Mymensingh City in Bangladesh
}

\author{
Sarah Yasmin ${ }^{1}$, Nur-E-Abir Sowrove ${ }^{1}$, Tasnim Haque ${ }^{1} \&$ Mohammad Ismail Hossain $^{1}$ \\ ${ }^{1}$ Department of Agribusiness and Marketing, Bangladesh Agricultural University, Bangladesh \\ Correspondence: Sarah Yasmin, Associate Professor, Department of Agribusiness and Marketing, Bangladesh \\ Agricultural University, Bangladesh.
}

Received: January 29, 2021 Accepted: February 18, 2021 Online Published: March 17, 2021

The research is financed by corresponding author own fund (self-fund).

\begin{abstract}
The study examined the factors influencing yearly consumption of turkey meat in Mymensingh city area. Data were collected from 60 consumers of turkey meat through Purposive sampling technique and face to face interview. Dummy coding was applied to code independent variables which were categorical in nature and multiple linear regression was carried out to find out the factors influencing consumption of turkey meat. Result indicated that the majority of the consumers (more than 50\%) favored taste, color and aroma of turkey meat. The findings also revealed that age $(\mathrm{P}<0.05)$ and monthly family income $(\mathrm{P}<0.01)$ were significantly influencing yearly consumption of turkey meat among consumers in Mymensingh city. The major difficulty faced by the turkey farmer recognized as unavailability of turkey feed in the market, high price of day-old chick, lack of access to agricultural credit, lack of training and marketing facility and un-availability of vaccines. Analyzing the factors affecting consumption of turkey meat would facilitate in marketing decision making process of the turkey farmers and also deliver information to policy makers of Government as well as Department of Livestock Services to take necessary initiatives and support this alternative meat source to rise as a popular consumer choice.
\end{abstract}

Keywords: consumption, factors, meat, Mymensingh, turkey

\section{Introduction}

Turkey (Meleagris gallopavo) is a large gallinaceous bird of the family Meleagridae that is inherent in North America, retained in Europe and are currently a vital source of food in various parts of the world (Turkey Management Guide, 2012). Turkeys are very much social with humans and their rearing are really enjoyable. Many farmers are rearing turkeys as a hobby. Consistently, turkey birds are reared for meat purposes. Though turkey meat is not only considered the leanest meat among all domestic avian species but also luxury meat by numerous consumers. Turkey is getting recognition amongst the rural area in Bangladesh for the reason that its improved and sophisticated meat production, minimum production cost and increased self-employment opportunities (Miah et al., 2020). Recently, turkey farming is comparable to other poultry birds farming like chickens, ducks, quails etc. It occupies a key global position following chicken and duck approximately $5 \%$ of world poultry population (Besbes, 2009). Turkey production is an imperative and highly profitable agricultural industry with rising global demand for its products (Yakubu et al., 2013). According to Asaduzzaman et al. (2017), main advantages of turkey rearing over other poultry species are high disease resistance capacity, high market price, low feeding cost and mortality rate.

Rearing of turkey is a commercial farming practice to fulfill the protein necessity in developing countries like Bangladesh (Ali et al., 2019). Nutritionally, per 100 gm of turkey meat comprised $24 \%$ protein, $6.6 \%$ fat and 162 calories. Also, various minerals such as potassium, calcium, magnesium, iron, selenium, zinc and sodium are rich in turkey meat. It also contains the essential amino acids and vitamins like niacin, vitamin $\mathrm{B}_{6}$ and $\mathrm{B}_{12}$, respectively. Likewise, it has a great source in unsaturated fatty acids and essential fatty acids and low in cholesterol (Turkey management Guide, 2012). Apart from its nutritional role, the birds have an aesthetic value due to their beauty (Ogundipe and Dafwang, 1980).

As, it is a recently familiarized poultry bird in Bangladesh, interested farmers started turkey farming by importing day-old turkey chicks (Poult) from neighboring countries like India (Famous et al., 2019). Later, the birds quickly 
adjusted with local environment and thrived well under very ordinary foods, housing and management. Turkey farming was not much popular to the general farmers, primarily because the birds were not well known to poultry keepers. As well, Rahman (2019) investigated the performance and prospect of turkey production in Bogra district of Bangladesh and found that $34.78 \%, 19.57 \%$ and $45.65 \%$ respondent farmers were rearing turkey for ornamental, both egg and meat, and both meat and ornamental purposes, respectively. According to Jahan et. al. (2018), turkey grows faster like broiler chickens and becomes suitable for slaughter purpose within a very short time. Appropriateness of climatic situation, accessibility of regular feed and manpower can make turkey sector commercial, particularly for the poor and marginal farmers (Rashid et al., 2020).

It is however interesting to note that in recent days a good number of farmers became familiar with the bird, rearing 50-200 birds at the home premises and getting benefit by selling poults with high market price. Currently, market price of turkey poults is approximately Tk. 100/poult, which is much higher than the commercial chicken layer (Tk. 25/chick), broiler (Tk. 35 /chick), Sonali (Tk. 15/chick) and duck (Tk.30/duckling) (Das et. al., 2018). Famous et al. (2019) investigated that majority of the turkey farmers practice turkey in small scale semi-intensive system and they have lack of knowledge about variety of turkey, breed and prevention of diseases of turkey.

Moreover, Salawu et. al. (2014) conducted consumption and consumer preference for poultry meat types in Ibadan Metropolis and found different level of preference for the meat types recording total of $94.7 \%$ for broilers, $93.3 \%$ for cockerel and turkey while $90 \%$ was noted for layers. Kwadzo et. al. (2013) found taste, availability and proximity are vital attributes, which affects the consumers preference in purchasing broiler meat. Consumers are now demanding food products that are safe and are of good quality at a reasonable price (Liana et al., 2010). The attitude of consumers towards food, especially meat, is characterized by changing preferences (Becker et al., 2000). Sowrove et al. (2020) reported that the consumers in Mymensingh city have shown a favorable attitude towards turkey meat. However, as turkey is a new poultry species in Bangladesh, little research had been done on turkey and study on influencing socio-economic factors of turkey meat consumption in Bangladesh is very rare. So, it is essential to find out the factors which influence the consumption of turkey meat among the consumers. Therefore, the present study is aimed to determine the socio-economic factors that influence the consumption of turkey meat.

\section{Method}

\subsection{Selection of the Study Area, Sample and Period of Data Collection}

Mymensingh city area (Figure 1) was purposely chosen for the study as it is a city with rising demand and enormous prospective for turkey meat. Selected samples comprising 60 consumers and primary data were collected during the month of August and September, 2019 for this study. For identification of problems, the commercial turkey farm owner was considered as the population for this study. The turkey farm owners were selected by applying purposive sampling technique. The farms whose ages were less than one month of age were not included in the sample. Selected samples consisted of 40 turkey farm owners.

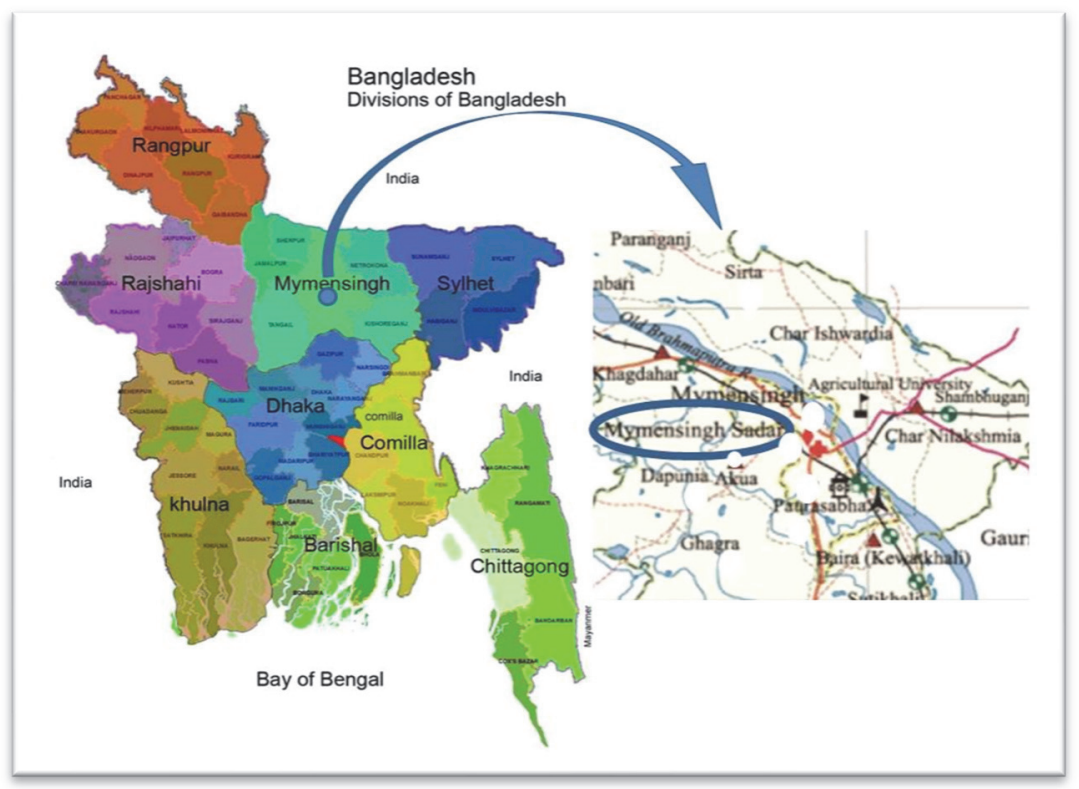

Figure 1. Map of Mymensingh city showing the sample collection site in Bangladesh 


\subsection{Methods of Data Collection}

Necessary data had been collected by the researcher himself through using questionnaires and face to face interviews. In addition, the researcher also accumulated data through numerous previous research works, web information, several journals and magazines. Before beginning the interview, each respondent was given a short explanation about the objectives of the study. Then the questions were asked with a simple manner by details of each question.

\subsection{Processing and Tabulation of Data}

After collection of data from the field, all data for the present study were edited, coded, tabulated, summarized and processed for analysis. The data had been transferred into the MS Excel sheet from the interview schedules. Finally, required numbers of tables had been prepared and results were obtained by using various statistical techniques.

\subsection{Analytical Techniques}

\subsubsection{Consumer's Opinion About Turkey Meat}

To find out attributes influencing consumers opinion about turkey meat consumers were given a five point scale of Not Preferred, Least Preferred, Moderate Preferred, Preferred, Most preferred for different attributes of turkey meat namely taste, color, aroma, texture and appearance. Then percentage and frequency were used to find out consumers' perception about certain attributes of turkey meat.

\subsubsection{Testing Multicollinearity Among Independent Variables}

Multicollinearity exists when independent variables are correlated. Correlated independent variables make it difficult to make inferences about individual regression coefficient and their individual effects on the dependent variable. The variance inflation factor was applied to test the multicollinearity among the independent variables. It is usually written as VIF. A value of VIF is greater than 10 is considered as unsatisfactory, indicating that the independent variable should be removed from the analysis.

\subsubsection{Empirical Model (Multiple Linear Regression)}

To determine the factors affecting the consumption of turkey meat, a multiple linear regression model was conducted by taking yearly consumption of turkey meat as dependent variable and socio-economic variables as independent variables. The multiple linear regression model is given by the following equation:

$$
\mathrm{Y}=\mathrm{A}+\Sigma \mathrm{B}_{\mathrm{i}} \mathrm{X}_{\mathrm{i}}+\mathrm{U}_{\mathrm{i}}
$$

The Model was simplified as,

$$
\mathrm{Y}=\mathrm{A}+\Sigma \mathrm{B}_{\mathrm{i}} \mathrm{X}_{\mathrm{i}} \quad ; \quad \mathrm{i}=1,2,3 \ldots \ldots
$$

Where, $\quad \mathrm{Y}=$ Yearly turkey meat consumption $(\mathrm{Kg})$

$$
\mathrm{A}=\text { Intercept }
$$

$\mathrm{X}_{1}=$ Religion, $\mathrm{X}_{2}=$ Gender, $\mathrm{X}_{3}=$ Age, $\mathrm{X}_{4}=$ Number of family member, $\mathrm{X}_{5}=$ Monthly family income

This method represents group membership with dummy variables that take on values 0 and 1 . Membership in a particular group is coded one, whereas non-membership in the group is coded zero. In most common applications, one group receives zeros on all dummy variables and functions as the reference group (Cohen and Cohen, 1983; Myers and Well, 2003). When dummy coding is used in the regression analysis, the overall results indicate whether there is a relationship between the dummy variables and the dependent variables. The values of the intercept and the regression coefficients of the resulting regression model can be obtained using least squares estimation procedures (Allen, 1997; Cohen and Cohen, 1983). Regression model using dummy coding can be written as:

$$
Y_{i j}=B_{0}+B_{j} D_{i j}+U_{i j}
$$

Where,

$\mathrm{Y}_{\mathrm{ij}}$ : The score on the dependent variable for subject $\mathrm{i}$ in group $\mathrm{j}$.

$\mathrm{B}_{0}$ : The intercept that represents the mean of the group coded 0 on all the dummy variables.

$B_{\mathrm{j}}$ : The regression coefficient associated with the jth group, and it represents the difference between the mean of the group coded 1 on the corresponding dummy variable and the mean of the group coded 0 on all the dummy variables.

$D_{\mathrm{ijj}}$ : The numerical value assigned to subject $\mathrm{i}$ in the jth group.

$\mathrm{D}_{1}=$ Religion (hindu and muslim), $\mathrm{D}_{2}=$ Gender (male and female), $\mathrm{D}_{3}=$ Family size (small size and large size) 
$\mathrm{U}_{\mathrm{ij}}$ : The error associated with the ith subject in the jth group.

The general rule of coding states that all members of a given group are assigned identical numerical values. It follows that their predicted scores are also identical. The predicated score for each subject is equal to the mean of the group to which the subject belongs. In addition, the coefficient of multiple determination, $\mathrm{R}^{2}$, for the regression model with dummy variables can be interpreted in terms of the proportion of variance in the dependent variable that is accounted for by the categorical independent variable (Allen, 1997; Cohen and Cohen, 1983; Keppel and Zedeck, 1989; Myers and Well, 2003). Dummy coding is the preferred method when one wishes to compare several treatment groups with a control group. In this case, the control group may serve as the reference group and the regression coefficients would then reflect the treatment-control mean differences (Myers and Well, 2003).

\section{Results and Discussion}

\subsection{Attributes Influencing Consumer's Opinion About Turkey Meat}

The results of the assessment done by the respondents on various attributes of turkey meat under most preferred, preferred, moderate preferred, least preferred and not preferred categories are presented in Table 1 . The taste $(68.3 \%)$ is the most favored attribute (calculated by summing up the percentage of preferred and most preferred) followed by color $(66.67 \%)$, aroma (61.67\%) and texture (48.33\%). The appearance is the lowest favored attribute of turkey being only $8.34 \%$ favored. This result is affirmed by Senthilkumar and Muralidhar (2014), taste of the meat had a very good influence on meat consumption in rural areas with an average mean score of 54.73.

Table 1. Consumer's assessment on turkey meat $(\mathrm{N}=60)$

\begin{tabular}{cccccc}
\hline \multirow{2}{*}{ Attributes } & \multicolumn{5}{c}{ Number of consumers } \\
\cline { 2 - 6 } & Not Preferred & Least Preferred & Moderate Preferred & Preferred & Most preferred \\
\hline Taste & $1(1.67)$ & $9(15)$ & $9(15)$ & $29(48.3)$ & $12(20)$ \\
\hline Color & $0(0)$ & $7(11.67)$ & $13(21.67)$ & $22(36.67)$ & $18(30)$ \\
\hline Aroma & $0(0)$ & $10(16.67)$ & $13(21.67)$ & $21(35)$ & $16(26.67)$ \\
\hline Texture & $2(3.33)$ & $9(15)$ & $20(33.33)$ & $20(33.33)$ & $9(15)$ \\
\hline Appearance & $35(58.33)$ & $15(25)$ & $5(8.33)$ & $4(6.67)$ & $1(1.67)$ \\
\hline
\end{tabular}

Source: Field Survey, 2019; Note: Figures in the parentheses indicates percentage

\subsection{Multicollinearity Testing Among the Independent Variables}

The value of VIF of independent variables indicated that the independent variables were not strongly correlated with one another (Table 2) which is consistent with the result of Rahman et al. (2020) who found significant differences in consumption level were observed among the age categories, profession, gender, education, and income levels.

Table 2. Testing multicollinearity among independent variables

\begin{tabular}{cl}
\hline Variables & VIF \\
\hline Religion & 1.685802 \\
\hline Gender & 1.971109 \\
\hline Age & 1.995741 \\
\hline Number of Family member & 3.897406 \\
\hline Monthly family income & 3.283924 \\
\hline
\end{tabular}

Source: Field Survey, 2019

\subsection{Contributing Factors for Consumption of Turkey Meat}

Result of the regression analysis is shown in Table 3. It was found that the coefficient of the religion had positive but statistically insignificant impact on turkey meat consumption (Table 3). Withal, the result indicated that Muslim families are likely to consume more turkey meat than a Hindu family. This result is divergent by Higenyi et al., (2014) who found that socio-demographic characteristics like religion were very significant ( $p$-value $<0.05$ ) 
determinants of consumer choice in case of duck meat. The reason behind this phenomenon might be due to the fact that most of the Hindu families had a higher number of elderly people who were very conservative and did not appreciate a foreign bird meat in family dining. Thus Hindu families were found to be consuming less of turkey meat than Muslim families.

Table 3. Multiple linear regression analysis of factors influencing yearly consumption of turkey meat $(\mathrm{Kg})$

\begin{tabular}{ccc}
\hline Selected Variables & Co-efficient & P value \\
\hline Intercept & 1.78 & 0.007 \\
Religion & 2.95 & 0.33 \\
Gender & 1.89 & 0.57 \\
Age & $0.27^{* *}$ & 0.04 \\
Number of Family member & 0.67 & 0.59 \\
Monthly family income & $0.0007^{* * *}$ & 0.00 \\
F Statistics & \multicolumn{2}{c}{3.56} \\
$\mathrm{R}^{2}$ & \multicolumn{2}{c}{0.79} \\
Adjusted R & \multicolumn{2}{c}{0.82} \\
DF & \multicolumn{2}{c}{59} \\
\hline
\end{tabular}

Source: Field Survey, 2019

Gender is deliberated to be a vital factor in consumer attitude. The co-efficient of the gender had found positive influence on turkey meat consumption in the regression analysis (Table 3). The regression model took female samples consumption as the base to explain male samples consumption. From Table 3, it was observed that a male consumed $1.89 \mathrm{~kg}$ more turkey meat than a female yearly. Sacl (2018) who revealed that gender is recognized as a factor affecting the consumption of chicken meat in turkey. Furthermore, Gossard and York (2003) stated that gender had a strong impact on meat consumption in US residents. According to their opinion, men physiologically needed additional meat rather than women because of the weight dissimilarities.

The co-efficient of age had found a positive impact on turkey meat consumption in the regression analysis and it was statistically significant at $5 \%$ level of significance. The result indicated that as the age of the consumer increases, consumption of turkey meat also increases. This result is consistent with Sacl (2018) who revealed that age determinant has statistically significant influence on meat consumption affinities of consumers, particularly targeting those who are 40 years old or younger people aiming to increase chicken meat consumption.

The regression result showed that the number of family members is positively related with consumption of turkey meat. Large family is likely to consume more turkey meat than small family. However, it was statistically insignificant. According to Uzunoz and Karakas (2014), red meat intake has declined with the rising number of persons in the family. Thus, there exists a negative association among red meat consumption and family size. This result is not supported with Uzunoz and Karakas (2014). The reason can be that family size is deliberated as a factor for clarifying the amount of turkey meat consumption. This factor is included in the regression model because more meat can be consumed by larger families.

The co-efficient of monthly family income had a positive impact on yearly turkey meat consumption. With $1 \%$ monthly family income is increased, yearly consumption of turkey meat is also increased by $0.0007 \%$ and it was statistically significant at $1 \%$ level of significance. This result is supported by Uzunoz and Karakas (2014) who found a positive and statistically significant association among consumers' income level and red meat consumption. In addition Mizrak et al. (2012) carried out a study who found that income as a significant determinant influencing the choice of chicken meat consumption. Moreover, according to Phuong et al. (2014), increasing income is one of the key factors that influence on rising meat consumption in Vietnam. Rising incomes have caused a greater demand for meat products. Family income is the foremost factor, determining consumers' consumption attitude. This variable is included in the model because low-income families may consume more turkey meat when their income rises. 


\subsection{Problems Faced by Turkey Farmer}

The turkey farmer faced various problems during farming and marketing. The production and marketing problems of turkey in the study areas are shown in Figure 2.

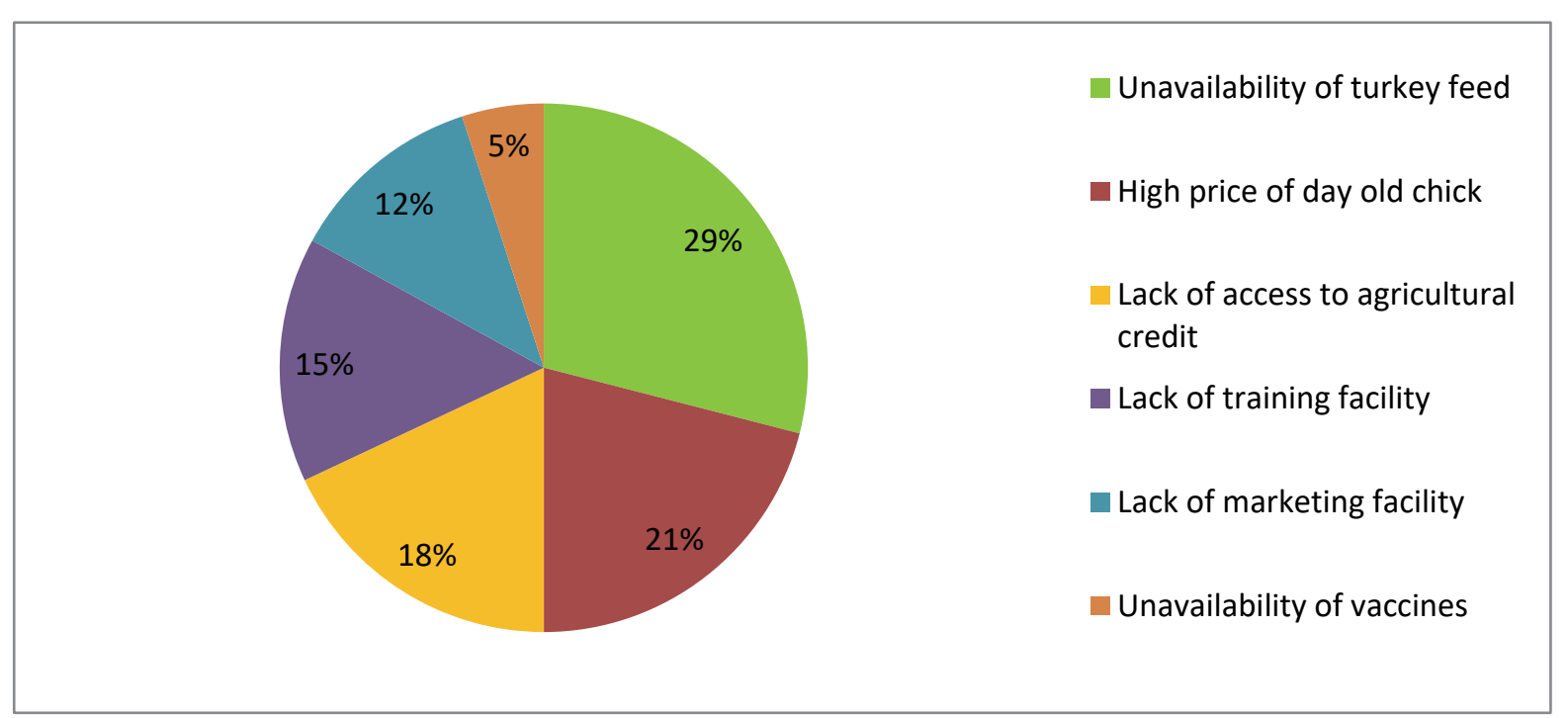

Figure 2. Associated problems in turkey farming in Mymensingh City, Bangladesh

From Figure 2, it is apparent that $29 \%$ respondents informed about the unavailability of turkey feed in the market. Producers were usually depending on scavenging nature of turkey in semi intensive rearing system and provided grower feed for chicken available in the market. Grower feed for broiler chicken may not provide enough nutrients necessary for optimal growth of turkey bird. Unavailability of feed in the market was not only a problem for the producers but also for middlemen in the marketing process who have to feed the bird until selling it. Figure 2 indicated that $21 \%$ respondents informed high price of day old chick. Likewise, $18 \%$ of the respondents said they were not provided with any agricultural loan for rearing turkey, as the risks of rearing turkey birds cannot be determined due to it being a new enterprise, financial institutes and credit suppliers were hesitant in giving credit to turkey farmers. Moreover, $15 \%$ respondents said they were not provided with any form of training on rearing system and management of turkey bird. Furthermore, $12 \%$ respondents said that there was no enough marketing facility for selling turkey bird in the market place because marketing channel and transportation facilities for turkey was not completely developed yet. Lack of vaccination is another problem of producing turkey and $5 \%$ respondents informed that unavailability of vaccines for turkey. The veterinarians could not recognize the main diseases because of it being a new breed and they have lack of knowledge about treatments and disease control. These results are consistent with Rashid et al. (2020) who found that 15.22\% turkey farmers faced low feed quality and higher price, $10.87 \%$ respondents informed that lack of proper marketing facility and $3.48 \%$ respondents said that lack of availability of training facility.

\subsection{Suggestions Provided by Turkey Consumers}

Figure 3 represents the certain steps need to be taken for increasing turkey consumption which identified during data collection. It is depicted that turkey consumer responded lower price, more supply of turkey, raising awareness will lead to increase more consumption of turkey meat. For this instance, Rashid et al. (2020) suggested that generating income, creating employment opportunities and proper managerial steps in turkey rearing could be a viable commercial enterprise in poultry sector and thus improving the living standard of the rural people. Also, Asaduzzaman et al. (2017) reported that vigorous public extension service, training for farmers, opening of different avenues for research on turkey and identifying marketing strategies, are immediately needed to improve the turkey production in Bangladesh. Thus to develop the turkey bird enterprise, the probable suggestions on the basis of response by the farmers were ensuring the supply of feed at reasonable price, monitoring the prices of day-old chick, providing institutional credit, effective training facilities, improving marketing facilities and providing veterinary support and vaccines. 


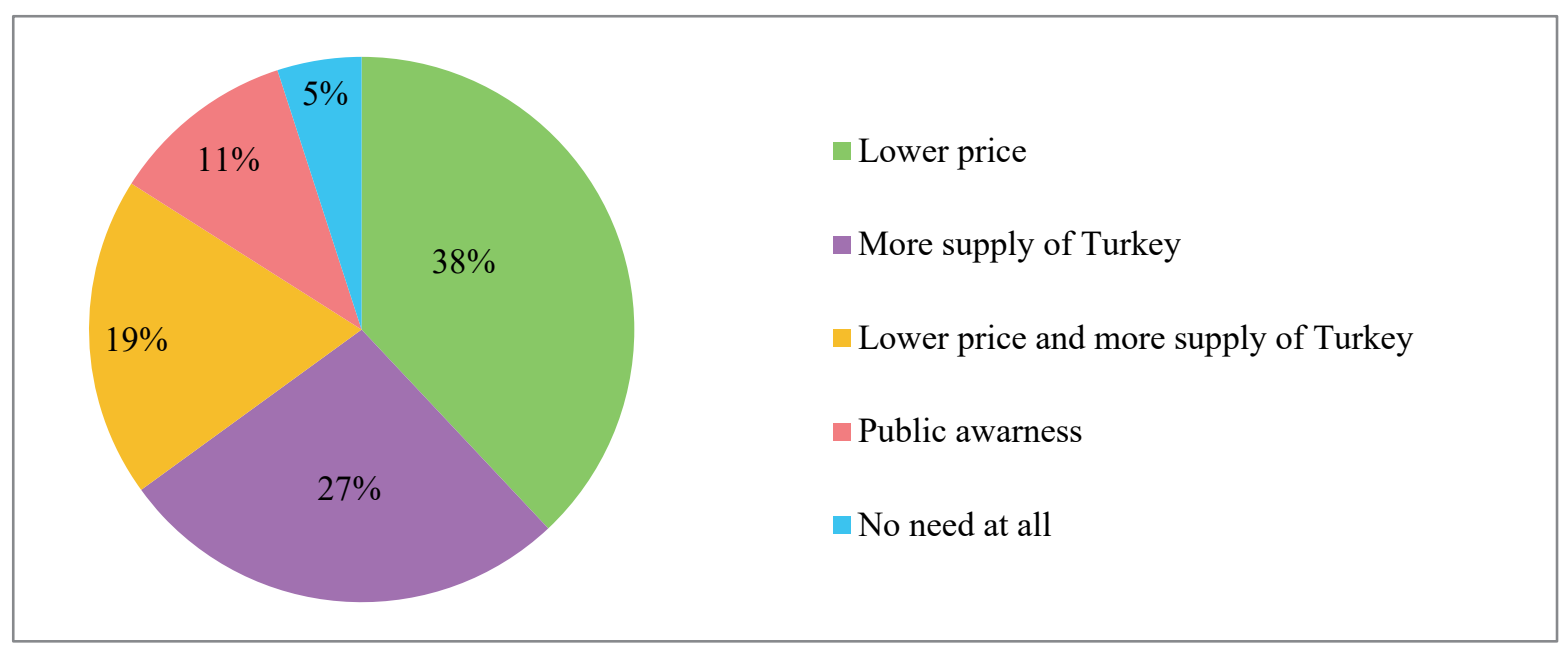

Figure 3. Consumer's opinion for increasing turkey consumption

\section{Conclusion}

Consumers are always seeking new variety of food due to change in taste and preference as well as variation in their lifestyles. Consumption of turkey meat is considered as festive food and an essential diet in Bangladesh. Socio-economic and demographic characteristics of the households played a significant contribution in creating consumer preference towards the turkey meat in Bangladesh. Taste and color of turkey meat was the most preferred attribute to the consumers and turkey meat is an extremely nutritious food. The variables which significantly influenced the consumers for turkey meat consumption were age and monthly family income. Factors that significantly influence consumption of turkey meat should be considered while preparing marketing plans, formulating policy and promotion of turkey farming for gaining better success in this enterprise. The most commonly faced problem is that there is no available turkey feed in the market. Timely availability of turkey feed at reasonable price in the market is essential to reduce this problem. Marketing infrastructure should be created to facilitate selling, processing and packaging of turkey meat. To hold and generate new turkey customers, farms should conduct customer surveys, develop new consumer groups and launch new value adding products. This study will help to learn that different factors play a significant role in determining the preference for turkey meat, provide some new information regarding this matter, and facilitate farmers who are associated with turkey rearing to understand its market potential and risks and policy makers may be able to adopt better agricultural policies for the improvement of turkey enterprise.

\section{Acknowledgement}

The authors would like to acknowledge the turkey consumer of Mymensingh city area for their huge support and co-operation during data collection. The author also would like to thank the Department of Livestock Service, Mymensingh for providing turkey and respondent information during the survey.

\section{References}

Ali, M. Y., Sarker, N. R., Ershaduzzaman, M., Khatun, R., Ahmed, S., Alam, M. A., \& Alam, U. S. (2019). Semiintensive rearing of turkey (Meleagris gallopavo) in some selected areas of Bangladesh. Asian-Australasian Journal of Food Safety and Security, 3(1), 48-52.

Allen, M. P. (1997). Understanding regression analysis [Electronic version]. New York: Plenum Press.

Asaduzzaman, M., Salma, U., Ali, H. S., Hamid, M. A., \& Miah, A. G. (2017). Problems and prospects of turkey (Meleagris gallopavo) production in Bangladesh. Research in Agriculture Livestock and Fisheries, 4(2), 7790.

Becker, T., Benner, E., \& Glitsch, K. (2000). Consumer perception of fresh meat quality in Germany. British Food Journal, 102(3), 246-266.

Besbes, B. (2009). Genotype evaluation and breeding of poultry for performance under sub-optimal village conditions. World's Poultry Science Journal, 65, 260-271. https://doi.org/ 10.1017/S0043933909000221

Cohen, J., \& Cohen, P. (1983). Applied multiple regression/correlation for the behavioral sciences (2nd ed.) 
[Electronic version]. Hillsdale, NJ: Lawrence Erlbaum Associates.

Das, S. C., Yahya, M., Hasan, M. S., Hossain, M. A., Akter, T., \& Sultana, M. (2018). Growth performance of white, black and bronze color heritage turkeys under semi-intensive system. Journal of the Bangladesh Agricultural University, 16(3), 471-477.

Famous, M., Islam, O., Khatun, S., Rahman, M. M., \& Ferdoushi, T. (2019). Feeding and management system of turkey in the Sylhet region, Bangladesh. Veterinary Sciences: Research and Reviews, 5(2), 58-65.

Gossard, M. H., \& York, R. (2003). Social structural influences on meat consumption. Human Ecology Review, $10(1), 1-9$.

Higenyi, J., Kabasa, J. D., \& Muyanja, C. (2014). Social factors and quality attributes influencing preference for production of local poultry in Butaleja and Tororo, Eastern Uganda. Animal and Veterinary Sciences, 2(1), 10-17. https://doi.org/10.30560/as.v2n2p28

Jahan, B., Ashraf, A., Rahman, M. A., Molla, M. H. R., Chowdhury, S. H., \& Megwalu, F. O. (2018). Rearing of high yielding turkey poults: problems and future prospects in Bangladesh. SF Journal of Biotechnology and Biomedical Engineering, 1(2), 1008.

Keppel, G., \& Zedeck, S. (1989). Data analysis for research designs: analysis of variance and multiple regression/correlation approaches. New York: W.H. Freeman and Company.

Kwadzo, G. T., Dadzie, F., Osei-Asare, Y. B., \& Kuwornu, J. K. (2013). Consumer preference for broiler meat in Ghana: a conjoint analysis approach. International Journal of Marketing Studies, 5(2), 66-73.

Liana, M., Radam, A., \& Yacob, M. R. (2010). Consumer perception towards meat safety: Conformatory Factor Analysis. International Journal of Economics and Management, 4(2), 305-318.

Miah, G., Khanom, M. F., Lima, A., Sohel, M. S. H., \& Hossain, M. A. (2020). Comparative performance of three varieties of turkey (Meleagrisgallopavo) raised under semi-intensive system. Bangladesh Journal of Veterinary and Animal Sciences, 8(1), 29-34.

Mızrak, C., Durmuş, İ., Kamanli, S., Demirtaş, S., Kalebaşi, S., Karademir, E., \& Doğu, M. (2012). Determination of egg consumption and consumer habits in turkey. Turkish Journal of Veterinary and Animal Sciences, 36(6), 592-601. https://doi.org/10.3906/vet-1102-778

Myers, J. L., \& Well, A. D. (2003). Research design and statistical analysis (2nd ed). Mahwah, NJ: Lawrence Erlbaum Associates.

Ogundipe, S. O., \& Dafwang, I. I. (1980). Turkey production in Nigeria. National Agricultural Extension Research and Liaison Service (NAERLS) Bulletin 22, 2-22.

Phuong, N. V., Cuong, T. H., \& Mergenthaler, M. (2014). Effects of socio-economic and demographic variables on meat consumption in Vietnam. Asian Journal of Agriculture and Rural Development, 4(1), 972-987.

Rahman, M. (2019). Performance and prospect of turkey production in Bogura district of Bangladesh. A production report submitted in partial satisfaction of the requirements for the degree of Doctor of Veterinary Medicine Faculty of Veterinary Medicine Chittagong Veterinary and Animal Sciences University Khulshi, Chittagong4225, Bangladesh.

Rahman, M. N., \& Islam, A. R. M. T. (2020). Consumer fish consumption preferences and contributing factors: empirical evidence from Rangpur City Corporation, Bangladesh. Heliyon, 6(12), 1-10. https://doi.org/10.1016/j.heliyon.2020.e05864

Rashid, M. A., Rasheduzzaman, M., Sarker, M. S. K., Faruque, S., Palash, M. S., \& Sarker, N. R. (2020). Smallscale turkey farming in Bangladesh: farming practices, profitability and supply chain mapping. Agricultural Science, 2(2), 28-41.

Sacl, Y. (2018). Evaluation of socio-economic factors affecting chicken meat consumption in turkey. Journal of Poultry Research, 15(2), 47-52.

Salawu, M. B., Ibrahim, A. G., Lamidi, L. O., \& Sodeeq, A. E. (2014). Consumption and consumer preference for poultry meat types in Ibadan Metropolis. Journal of Economics and Sustainable Development, 5(28), $20-25$.

Senthilkumar, T., \& Muralidhar, V. (2013). Factors influencing meat buying behaviour among rural, semi-urban and urban households. International Journal of Science and Research, 5(2), 317-318.

Troy, D. J., \& Kerry, J. P. (2010). Consumer perception and the role of science in the meat industry. Meat Science, 86(1), 214-226. CrossRef, PubMed. https://doi.org/10.1016/j.meatsci.2010.05.009 
Uzunoz, M., \& Karakas, G. (2014). Socio-economic determinants of red meat consumption in turkey: a case study. Çankırı Karatekin Üniversitesi SBE Dergisi, 5(1), 037-052.

Yakubu, A. K., Abimiku, I. S., Azara, M., Idahor, K. O., \& Akinsola, O. M. (2013). Assessment of flock structure, preference in selection and traits of economic importance of domestic turkey (Meleagris gallopavo) genetic resources in Nasarawa state, Nigeria. Livestock Research for Rural Development, 25(1), 18.

\section{Copyrights}

Copyright for this article is retained by the author(s), with first publication rights granted to the journal. This is an open-access article distributed under the terms and conditions of the Creative Commons Attribution license (http://creativecommons.org/licenses/by/4.0/). 